\section{Signal utilization under a discriminated avoidance schedule*}

\author{
HARRY M. B. HURWITZ, PAUL V. DILLOW†, and HARRY DeNISE $\dagger+$ \\ University of Tennessee, Knoxville, Tenn. 37916
}

Four rats were trained under a temporally defined avoidance schedule composed of time period $t^{\Delta}$, during which responses had no programmed consequences, and $t^{\mathbb{D}}$, during which responses precluded shock. When a signal was programmed to last throughout $t^{D}$ and was response terminable, responses occurred primarily during the signal. A brief signal at the beginning, middle, or the end of the $t^{D}$ period had little effect on behavior. When the signal was programmed throughout $t^{D}$, avoidance declined, and the response rate in $t^{D}$ was greater than when the signal was terminable by a response.
Under a conventional discriminated shock avoidance procedure, $a \mathrm{~S}$ is presented with a signal (CS) to indicate that shock will occur unless the required response is made. The CS may develop different functions: it may act as a conditioned aversive stimulus which elicits generalized emotional responses; it may act as a conditioned avoidance stimulus in that under some conditions Ss will learn to prevent its onset; it may arouse fear, for Ss will learn to escape from it; it may act as a discriminative stimulus since Ss learn to respond only in the often suppresses ongoing behavior. The present experiment investigated whether or not Ss who have learned to avoid shock make use of a CS, a problem that has received relatively little study (Hyman, 1969).

Ss were first trained under a nondiscriminated shock avoidance procedure which consisted of three components: $t \Delta$, a period during which responses had no programmed effects; $t^{D}$, a period during which the referent response precluded a shock which would otherwise occur after $t^{D}$ had terminated, and $t^{S}$, the period during which shock could occur. The three periods were presented in the sequence $t^{\Delta}, t^{D}, t^{S}$ and together defined the cycle T. A signal was introduced during the whole or part of thy period $t D$ after the level of avoidance had stabilized, and the question was whether the $\mathbf{S}$ would use the signal, by a change in the response rate, or whether they would adhere to the response strategy developed earlier, before the signal was introduced.

* This research was supported by NSF Reprints may be obtained from Dr. H. M. B. Hurwitz, Department of Psychology, University of Tennessee, Knoxville, Tenn. 37916.

Now at Arizona State University, Tempe, Ariz. 85281.

$\dagger+$ Now at Emory University, Atlanta, Ga. 30322 . presence of the stimulus; finally, it Grant GB-8505 to Harry M. B. Hurwitz,

\section{SUBJECTS}

The Ss were four female hooded rats, obtained from Blue Spruce Farms, N.J. They were approximately 150 days old at the beginning of experimentation.

\section{APPARATUS}

Experimental sessions were conducted in a chamber measuring $225 \times 225 \times 200 \mathrm{~mm}$. The chamber was equipped with a grid floor, a ceiling lamp, and a response lever which activated a microswitch when a force of $0.09 \mathrm{~N}$ was applied. Electric shock $(0.5 \mathrm{~mA})$ was delivered to all parts of the chamber from a constant-current generator through a scrambler. The chamber was located in a ventilated sound-attenuated man-sized cubicle. Programming and recording facilities were located outside this cubicle.

\section{PROCEDURE}

The experiment consisted of nine phases. The procedures will be described in the order in which they were imposed.

\section{Phase 1}

Phase 1 replicated the procedure developed by Hurwitz \& Millenson (1961). A cycle, T, composed of three time periods was constructed. Each session was begun in period $t^{\Delta}$, which was followed by $t^{D}$ and $t^{S}$. The total cycle length was $37 \mathrm{sec}$, but the ratio of $t^{D} /\left(t^{\Delta}+t^{D}+t^{S}\right)$ was varied by varying the duration of $t \Delta$ and $t D$. Responses during $t \Delta$ had no programmed effects; the first response in $t D$ was effective in preventing shock at the end of the $t^{D}$; during $t s$ the first response terminated shock on those occasions when no response occurred in the preceding $t^{D}$ period. This phase of the procedure will be referred to as BASE. Each S was exposed to the set of conditions in Table 1.

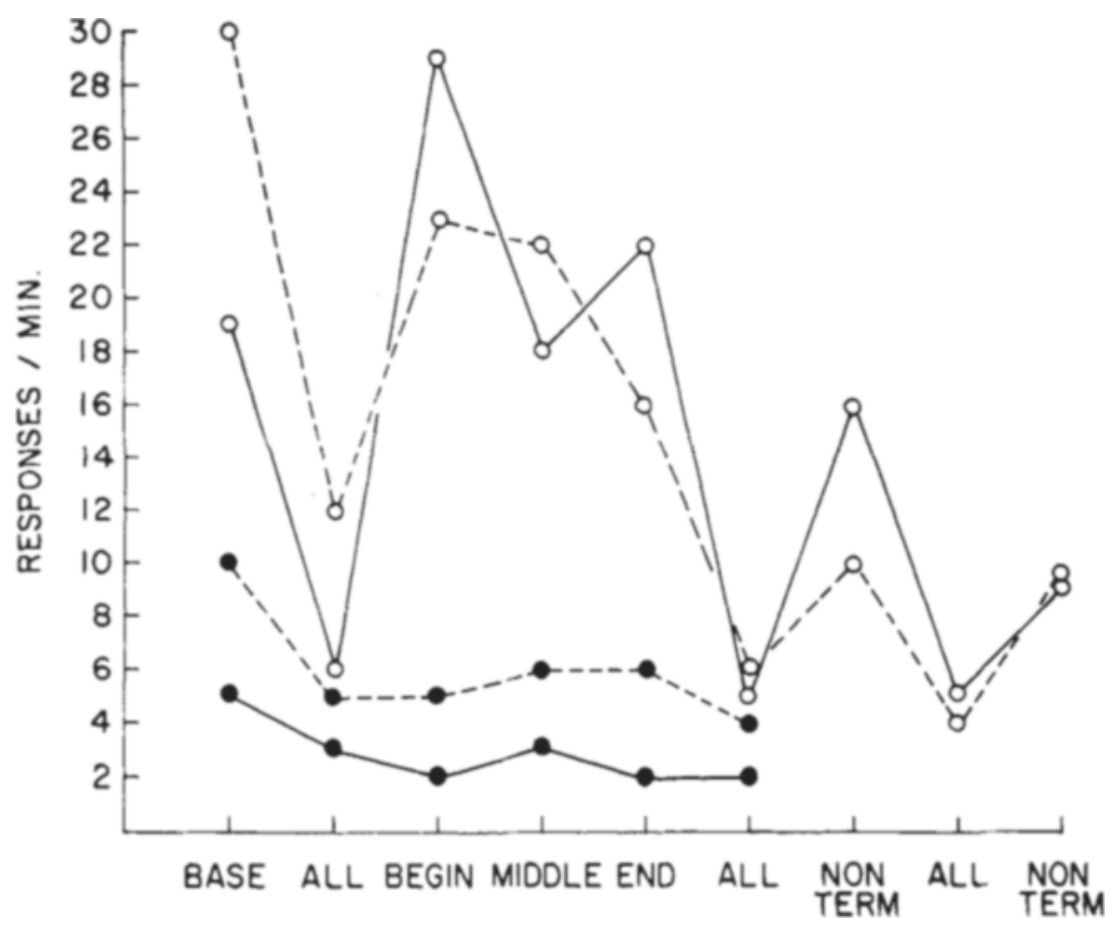

Fig. 1. Percent avoidance attained by Rats 1, 2, 3, and 4 under each phase of the experiment. The abscissa presents the signal presentation conditions in the order in which they were imposed: BASE-no signals; ALL-signal terminable by response presented throughout the warning period; BEGIN-1 sec signal at the beginning of the warning period; MIDDLE-1-sec signal in the middle of the period; ENG-1-sec signal at the end of the warning period; NONTERM-signal terminable by response. Rat 1-solid lines, closed circles; Rat 2-dotted lines, closed circles; Rat 3-open circles, closed lines; Rat $4 \multimap$ open circles, dotted lines. 
Table 1

\begin{tabular}{|c|c|c|c|c|}
\hline \multicolumn{4}{|c|}{ Condition } & \multirow{2}{*}{$\begin{array}{c}\text { Session and } \\
\text { Session Length }\end{array}$} \\
\hline$t^{\Delta}$ & $t^{D}$ & ${ }_{t} S$ & $\overline{\mathrm{T}}^{*}$ & \\
\hline 0 & 34.5 & 2.5 & 1.00 & $5 \times 4 h$ \\
\hline 25.75 & 8.75 & 2.5 & 0.254 & $10 \times 4 h$ \\
\hline 30.12 & 5.37 & 2.5 & 0.127 & $5 \times 4 h$ \\
\hline 25.75 & 8.75 & 2.5 & 0.254 & $10 \times 1.25 \mathrm{~h}$ \\
\hline
\end{tabular}

$* \bar{T}$ refers to the ratio of $t D /\left(t \Delta+t^{D}\right)$

Table 2

The Percentages of Avoidance and the Rate of Responding Under All Values of $\overline{\mathrm{T}}$ During Phase 1, the Base Condition, Before Signals Were Presented. All scores are averages for the last five sessions under each condition.

\begin{tabular}{|c|c|c|c|c|c|}
\hline \multirow[b]{2}{*}{$\mathrm{s}$} & \multirow[b]{2}{*}{ Measure } & \multicolumn{4}{|c|}{ Measure of $\bar{T}$ in the Order Enforced } \\
\hline & & 1.00 & .254 & .127 & .254 \\
\hline 1 & $\begin{array}{l}\text { Percentage of Avoidance } \\
\text { Responses Per Minute }\end{array}$ & $\begin{array}{l}87 \% \\
6.06\end{array}$ & $\begin{array}{r}55 \% \\
10.02\end{array}$ & $\begin{array}{l}39 \% \\
9.48\end{array}$ & $\begin{array}{l}34 \% \\
4.80\end{array}$ \\
\hline 2 & $\begin{array}{l}\text { Percentage of Avoidance } \\
\text { Responses Per Minute }\end{array}$ & $\begin{array}{l}73 \% \\
5.58\end{array}$ & $\begin{array}{l}62 \% \\
8.52\end{array}$ & $\begin{array}{r}43 \% \\
11.10\end{array}$ & $\begin{array}{l}52 \% \\
9.90\end{array}$ \\
\hline 3 & $\begin{array}{l}\text { Percentage of Avoidance } \\
\text { Responses Per Minute }\end{array}$ & $\begin{array}{l}94 \% \\
7.74\end{array}$ & $\begin{array}{r}88 \% \\
13.74\end{array}$ & $\begin{array}{r}65 \% \\
19.62\end{array}$ & $\begin{array}{r}85 \% \\
18.66\end{array}$ \\
\hline 4 & $\begin{array}{l}\text { Percentage of Avoidance } \\
\text { Responses Per Minute }\end{array}$ & $\begin{array}{l}91 \% \\
7.98\end{array}$ & $\begin{array}{r}90 \% \\
25.62\end{array}$ & $\begin{array}{r}84 \% \\
36.60\end{array}$ & $\begin{array}{r}90 \% \\
30.36\end{array}$ \\
\hline
\end{tabular}

Phase 2

The nondiscriminated schedule was replaced by a discriminated avoidance procedure by associating a signal, $\mathrm{S}^{\mathrm{D}}$, with the 8.75 -sec period of $\mathrm{t}^{\mathrm{D}}$ and the 2.5-sec period, tS (see also Dunn, Foster, \& Hurwitz, 1971). A response during $S^{\nu}$ terminated the signal and avoided (or terminated) shock. This phase has been labeled ALL. Ss 1,2 , and 4 were given 19 sessions of 100 cycles (approximately $1.25 \mathrm{~h}$ ); $\mathrm{S} 3$ was given 15 sessions. The responses in the different components of the cycle were separately recorded.

Phase 3

This phase has been called BEGIN because the signal was presented for $1 \mathrm{sec}$ at the beginning of the $t^{D}$ only. Each session consisted of 100 cycles; 10 sessions were given.

\section{Phase 4}

During this phase, a $1-\mathrm{sec}$ signal was presented 4 sec after the commencement of the $t^{D}$ period, and $4.5 \mathrm{sec}$ before $\mathrm{t}^{\mathrm{S}}$, i.e., during the MIDDLE of the functional period. A response during the signal did not terminate it. The first response during $t^{D}$ precluded shock. A response during the 4 -sec period before the signal was presented prevented shock but did not affect the occurrence of the signal. Ten sessions, each consisting of 100 cycles, were given.

\section{Phase 5}

The 1-sec signal was presented $7.5 \mathrm{sec}$ after onset of $\mathrm{t}^{\mathrm{D}}$, that is, $1 \mathrm{sec}$ before the shock. The phase has been called END. A response during the signal did not terminate it. Ten sessions, each consisting of 100 cycles, were given. response from 7.98 to 36.80 per minute.

Figure 1 shows the results of discrimination training in terms of the percentage of shocks avoided; Fig. 2 gives the results in terms of response rate and Fig. 3 in terms of the "discrimination index," namely, the ratio of rate of response in $t^{D}$ to the overall rate of response during the experimental session. The avoidance percentage data in Fig. 1 shows that Rats 3 and 4 maintained a high rate of avoidance under both ALL conditions. Rats 1 and 2, on the other hand, did not maintain the level of avoidance during Phase 6 reached in Phase 2. Similarly, the rate of response data shows that for these two Ss, successive changes in experimental conditions had no systematic effect.

Introducing a warning signal during the functional period, $\mathrm{t}^{\mathrm{D}}$, produced a dramatic change in performance for Rats 3 and 4: Rate of response declined from approximately 19 to 6 and from 30 to 12 , respectively, without affecting the percent of avoidance. As indicated by Fig. 3, most of the responses were confined to the signal period. The change in the signaling condition from ALL to BEGIN resulted in a decline of the discrimination index Both Ss now responded at equal rates during the nonfunctional period, $t \Delta$, and the functional period, $t^{D}$, as they had done earlier under the BASE condition. The effect of shifting the 1 -sec signal from the beginning to the MIDDLE of the functional period, $t^{D}$, produced a decline in response rate but no change in the discrimination index. When the signal was presented during the final second of the $t^{D}$ period (END condition), the rate of response for Rat 3 increased slightly, avoidance declined, but the discrimination index showed no change. When conditions were changed again to match Phase 2, the earlier ALL results were replicated: The response rate of both Ss declined, the avoidance level was $90 \%$, and the discrimination index rose sharply to 8 .

The importance of response-contingent signal termination was investigated in Phases 7,8 , and 9 . The experimental conditions in Phase 7 were similar to those of Phases 2 and 6 , except that the signal was coextensive with $t^{D}$ and $t S$ and could not be terminated by a response. Avoidance declined substantially in Rat 4 but only minimally in Rat 3 , whereas response rates increased. Restitution of the ALL condition-during which signals were again response terminated-produced high avoidance, low response rates, and a high index of discrimination. In 


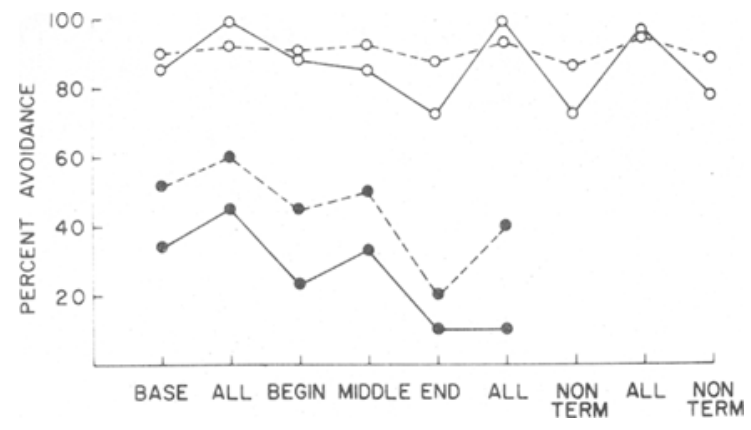

Fig. 2. Response rate per minute for Rats 1, 2, 3, and 4 under each phase of the experiment.

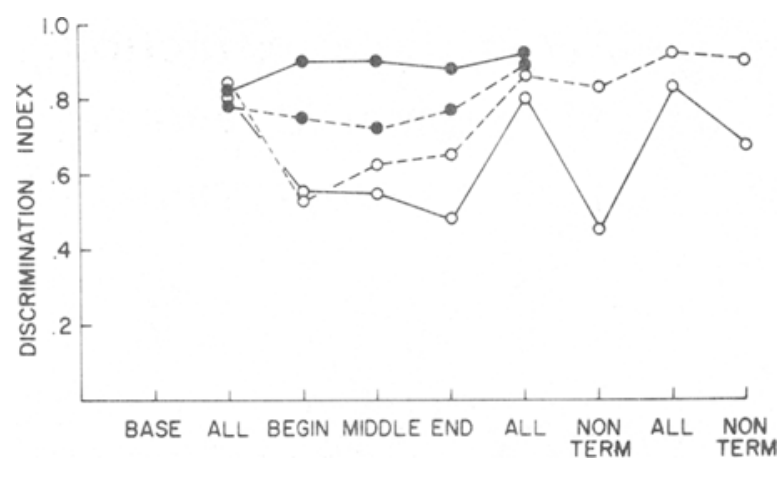

Fig. 3. Discrimination index computed as a ratio of rate of response in $\mathrm{t} \mathrm{D}_{\text {to }}$ the overall sessional response rate. Data from Rats $1,2,3$, and 4 are presented under each phase of the experiment.
Phase 9 the NONTERM condition was again imposed, response rates increased, the avoidance and the discrimination index again declined for Rat 3. Thus, the results of Phases 7 and 9 were similar.

\section{DISCUSSION}

Rats were first trained under a nondiscriminated avoidance schedule involving three temporal parameters: during $t^{\Delta}$, responses had no programmed effect; during $t^{D}$, a response avoided shock. If a $t D$ period elapsed without a lever response, a shock of limited maximum duration (tS) was presented. The shock could be terminated by a response. The present experiment replicated earlier results by Hurwitz \& Millenson (1961) since the response rate increased and avoidance declined as $t D$ decreased (BASE). The next step consisted of introducing a discriminative stimulus during the tD period. In Condition ALL, the stimulus (light) was presented during the whole $t^{D}$ period; a response in $t^{D}$ terminated the light and prevented shock. In Conditions BEGIN, MIDDLE, and END, a light of 1-sec duration was presented during the first, middle, and last second of the $t^{D}$ period, respectively; although a response during the 1 -sec stimulus was not effective in terminating the light, a response at any time during $t^{D}$ a voided $\mathrm{shock}$. Under Condition NONTERM, the light was presented continuously throughout the $t^{D}$ period; responses avoided shock but did not terminate the signal.

Under the BASE condition, two of the rats maintained approximately $85 \%$ avoidance (Rats 3 and 4 ), whereas the other two Ss (Rats 1 and 2) achieved only $35 \%-50 \%$ avoidance. The former Ss maintained their high level of avoidance throughout the entire series of signal manipulations described above, but avoidance in the latter Ss deteriorated progressively. Furthermore, their response rate and avoidance failed to recover when they were reexposed to the ALL condition. Our discussion will, therefore, center on the results of the two Ss who displayed sensitivity to the experimental procedures, namely, the good avoiders, Rats 3 and 4 .

Observations of overall response rate showed that Rats 3 and 4 drastically reduced their rates of response under the ALL condition; typically, only one response per signal occurred in contrast to continuous responding under the nondiscriminated BASE conditions. The fact that the $S s$ engaged in relatively high rates of leverpressing when a 1-sec signal, instead of a response terminable signal, was used suggests that these short signals were not effective discriminative stimuli.

Many writers have suggested that the termination of a warning signal is reinforcing so that responses which are instrumental in achieving signal termination would be differentially strengthened (e.g., Mowrer, 1950; Kamin, 1956). However, it is not clear whether or not the contingency relation between the response and signal termination is necessary to maintain the response. The results of Phases 7 and 9 suggest a partial answer; the response was maintained in the presence of the signal. Thus, the signal had acquired stimulus control over the response, and this function of the signal was not dependent on its being response-terminable. Such a result would be expected on the grounds that the response had originally been strengthened in the absence of warning signals in Phase 1; that is, the response had been strengthened by the shock avoidance schedule rather than the signal onset and termination conditions. The latter conditions served only to modulate the response rate established by the avoidance schedule, and it presumably did so by indicating appropriate occasions for responding.
In summary, when rats are given a choice between responding at a relatively high continuous rate to avoid shock or between making a single response following presentation of a signal, the characteristics of the signal appears to be a major determinant of the rat's preference. In the present experiment, signal duration and its temporal proximity to shock were varied. Evidently a light signal of 1 sec was not effective in controlling behavior irrespective of its proximity to avoidable shock, although light signals of long duration had previously controlled the S's behavior. Additional research is needed to establish the range of values of the stimulus preceding shock which would be acceptable as a signal for a $\mathrm{S}$. REFERENCES

DAVIS, H. Conditioned suppression: A review of the literature. Psychonomic Science Monograph Supplement, 1968 , 2(14, Whole No. 30), 283-291.

DUNN, M. E., FOSTER, W. S., \& HURWITZ, H. M. B. Rate of response as a function of $t \Delta$ length under a $t \Delta_{t} D$ avoidance schedule. Journal of the Experimental Analysis of Behavior, 1971, in press.

HURWITZ, H. M. B., \& MILLENSON, J, R. Maintenance of avoidance under temporally defined schedules. Science, $1961,131,284-285$.

HYMAN, A. Two temporal parameters of free operant discriminated avoidance in the rhesus monkey. Journal of the Experimental Analysis of Behavior, 1969 , 12, 641-648.

KAMIN, L. J. on avoidance learning. Journal of Comparative \& Physiological Psychology, 1956, 49, 420-424.

MOWRER, O. H. Learning theory and personality dynamics. New York: Ronald Press, 1950.

SIDMAN, M. Avoidance conditioning with brief shock and no exteroceptive warning signal. Science, 1953, 118, 157-158.

SIDM AN, M. Some properties of the warning stimulus in avoidance behavior. Journal of Comparative \& Physiological Psychology, $1955,48,444-450$

STRETCH, R., \& SKINNER, N. Methylphenidate and stimulus control of avoidance behavior. Journal of the Experimental Analysis of Behavior, 1967. $10,485-493$

ULRICH, R. E., HOLZ, W. C., \& AZRIN, N. H. Stimulus control of avoidance behavior. Journal of the Experimental Analysis of Behavior, 1964, 7, 129-133. 